\title{
Reloading a Variceal Rubber Band Ligator with Hemorrhoidal Bands: An Inexpensive and Effective Method
}

Ligation of esophageal varices is as effective as sclerotherapy, but has a lower incidence of complications (1). It has been regarded as the endoscopic treatment of choice for patients with esophageal variceal bleeding. In fact, the endoscopic ligating device is an adaptation of the technique of band ligation of hemorrhoids. Since rubber bands for ligation are expensive, reloading with inexpensive hemorrhoidal bands has been practiced in Hong Kong. The initial results seem to be satisfactory.

The aim of this prospective study was to examine the efficacy of this reloading method. Rubber band ligation was carried out with the Stiegmann-Goff ligator, on an Olympus Q230 video gastroscope. The ligating device was re-used after disinfection with glutaraldehyde for one hour. The O ring (Seward Medical, Ltd.) was disinfected with $2 \%$ glutaraldehyde for four minutes, and was loaded onto the ligating cylinder using the plastic cap of a ball pen (Figure 1). The device was then assembled, and the $\mathrm{O}$ ring was deployed in the usual way. On completion of the banding procedure, the endoscope was reinserted, and the number of slipped $\mathrm{O}$ rings was counted.

Eight patients were recruited for the study, with informed consent. In all, 71 rings were deployed in 16 endoscopic treatment sessions (mean 4.4 rings per session). Of the 71 rings deployed, 69 (97\%) were successfully placed. Two rings slipped off, probably due to leaking of the valve of the biopsy channel, resulting in inadequate suction force. With the exception of one patient with terminal hepatoma, there was no rebleeding.

Reloading a variceal rubber band ligator with hemorrhoidal rubber bands is therefore not only inexpensive, but also effective in the treatment of patients with esophageal variceal bleeding.

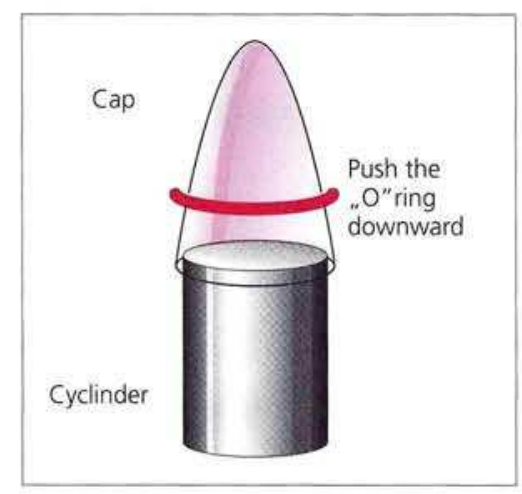

Figure 1: The method of reloading the rubber band ligator.

F. H. Ng', S. Y. Wong', S. T. Lai ${ }^{2}$, H. Y. Lo

' Dept. of Medicine, Ruttonjee Hospital, Hong Kong

${ }^{2}$ Dept. of Medicine, Princess Margaret Hospital, Hong Kong

${ }^{3}$ Dept. of Medicine, Queen Elizabeth Hospital, Hong Kong

\section{Reference}

1. Laine L, Cook D. Endoscopic ligation compared with sclerotherapy for treatment of esophageal variceal bleeding: a metaanalysis. Ann Intern Med 1995; 123: 280-7.

Corresponding Author

F. H. Ng, M.B., B.S., M.R.C.P, Dept. of Medicine

Ruttonjee Hospital, 266 Queen's Road East

Hong Kong, Fax: + 852-2836-1363 